treated 24 hours after infection showed disorganized globes. Three rabbits first treated 4 hours after infection by retrobulbar injection also did well, whilst 2 rabbits first treated 24 hours after infection did badly.

We are indebted to $\mathrm{Mr}$. B. Helliwell of the Research Division, Glaxo Laboratories for technical help in the studies recorded in this and the two preceding papers.

\title{
REFERENCES
}

SorsBy, A. and Ungar, J. (1946).-Brit. Med. Jl., ii, p. 723.

(1948).-Brit. Ji. Ophthal. This issue, p. 857.

\section{PRELIMINARY NOTE ON THE TREATMENT OF HYPOPYON ULCER BY CRYSTALLINE PENICILLIN IN ADRENALIN IN DOSES IN EXCESS OF 50,000 UNITS INJECTED BY SUBCONJUNCTIVAL OR RETROBULBAR ROUTES}

\author{
BY \\ ARNOLD SORSBY and JOSEPH UNGAR \\ LONDON
}

WhILST the experimental results recorded in the two preceding studies were being. established, a parallel investigation was conducted clinically to establish whether the eye tolerates subconjunctival injections of more than 50,000 units of crystalline penicillin and whether the frequency of application could be reduced. The experimental results suggested that higher doses than 50,000 units have the two-fold advantage of giving a higher concentration of penicillin intra-ocularly and that thisconcentration persisted for longer than with the smaller doses. In an earlier study (Sorsby and Reed, 194ז) dosage of 50,000 units of crystalline penicillin in adrenalin at six hourly intervals was advocated. The new experimental data suggested that with injections of $1,000,000$ units in adrenalin the intervals might be prolonged to 48 hours.

The following brief notes are recorded to show that at this stage 6 hourly injections of 50,000 units of crystalline penicillin can safely and with advantage be replaced by doses of 500,000 units of crystalline penicillin in adrenalin at intervals of 24 hours.

(1) Two cases treated by injection of 100,000 units in $0.5 \mathrm{ml}$. at 12 hourly intervals.

(a) A man, aged 37 years, with an infected corneal ulcer and a minimal hypopyon, showed no intolerance to subconjunctival 
injections of crystalline penicillin in doses of 100,000 units in 0.5 ml. of water at 12 hourly intervals. Within 24 hours the hypopyon had gone and injections were continued for three further days.

(b) A man, aged 56 years, with an infected corneal ulcer and a hypopyon occupying a quarter of the anterior chamber, likewise showed no intolerance to subconjunctival injections of 100,000 units of penicillin in $0.5 \mathrm{ml}$. of adrenalin at 12 hourly intervals. He required treatment for 4 days before the hypopyon disappeared.

(2) Use of 200,000 units at 24 ,hourly intervals.

In a case of hypopyon iritis in a woman, aged 29 , there was no intolerance-nor any response-to penicillin in doses of 200,000 units in $0.5 \mathrm{ml}$. of adrenalin at 24 hourly intervals. The injections were discontinued'after three days. The iritis and hypopyon subsided slowly on subsequent exclusive treatment by atropine and heat.

(3) Response to 300,000 units injected at 24 hourly intervals.

In a man, aged 50 , with a severe infected corneal ulcer and hypopyon occupying one quarter of the anterior chamber, the hypopyon disappeared after 5 subconjunctival injections of 300,000 units in $0.5 \mathrm{ml}$. water administered at 24 hourly intervals.

(4) Use of 400,000 units at 24 hourly intervals.

(a) In a man, aged 48 years, with a severe infected corneal ulcer, considerable iritis, but only minimal hypopyon, the hypopyon disappeared within 24 hours of a subconjunctival injection of 400,000 units in adrenalin. A second injection of 500,000 units in adrenalin was then given retrobulbarly. Recovery subsequently was uneventful under exclusive atropine therapy.

(b) A man, aged 37 years, with a hypopyon in a leucomatous eye, with considerable iritis and no corneal ulcer failed to respond to three subconjunctival injections of 400,000 units penicillin in adrenalin. After a protracted course the condition ultimately subsided. (This was probably a case of hypopyon iritis rather than of infection.)

(5) Use of 500,000 units at 24 hourly intervals.

These preliminary results have been followed by the use of penicillin in doses of 500,000 units at 24 hourly intervals. In four patients injections in $0.5 \mathrm{ml}$. adrenalin were used subconjunctivally; in two more the injections were given retrobulbarly.

\section{Three cases treated by subconjunctival injections}

(a) A boy, aged 17 years, was admitted with a minimal hypopyon, infected ulcer, and mild iritis. There was a history of a 
foreign body removed four days previously; the culture showed staphylococci and pneumococci. He was given two injections of 500,000 units penicillin in $0.5 \mathrm{ml}$. adrenalin at intervals of 24 hours. The hypopyon disappeared within the first 24 hours. There was an uneventful recovery and he was discharged after six days.

(b) A woman, aged 34 years, with an old corneal leucoma following scarlet fever in childhood, showed a minimal hypopyon. Within 24 hours after subconjunctival injection of 500,000 units penicillin in adrenalin the hypopyon had almost gone. After two further injections at intervals of 24 hours the lesion had subsided.

(c) A man, aged 54 years, was admitted with minimal hypopyon following the removal of a foreign body some days earlier. The culture was sterile. One injection of 500,000 units penicillin in adrenalin subconjunctivally led to the disappearance of the hypopyon within 6 hours.

(d) A boy, aged 12 years, developed a hypopyon-rather more than minimal-four days after removal of a corneal foreign body. Two hours after subconjunctival injection of 500,000 units of penicillin in adrenalin, the hypopyon had disappeared. A further injection was given 24 hours later. Recovery was uneventful.

\section{Two cases treated by retrobulbar injection}

(a) A man, aged 47, showed a hypopyon filling a quarter of the anterior chamber. This followed impaction of a foreign body on the cornea seven days earlier. The conjunctival sac was bacteriologically sterile. There was no response to one dose of 500,000 units penicillin in adrenalin injected retrobulbarly, nor to two subsequent subconjunctival injections of the same dose at 24 hourly intervals. He responded well to a course of sulphamezathine.

(b) A man, aged 56, showed a hypopyon filling one quarter of the anterior chamber following the impaction of a foreign body on the cornea nine days previously. A corneal ulcer had developed after the removal of a foreign body: this had been treated in the outpatient department for eight days. On the onset of a rapidly forming hypopyon he was admitted to the wards and the condition cleared completely within 24 hours after a single injection of 500,000 units penicillin in adrenalin retrobulbarly.

The use of $0.5 \mathrm{ml}$. of adrenalin $1: 1,000$ as a solvent is apparently a safe procedure. Some patients are said to be particularly susceptible to adrenalin, and as a precautionary measure it would seem wise, that, where adrenalin is used, the patient's reaction should first be tested by injecting 1 minim of adrenalin $1: 1,000$ subcutaneously. Susceptible patients are said to show transient symptoms of collapse. 


\title{
Summary
}

(1) The cocainized eye tolerates subconjunctival injections of crystalline penicillin in doses of 100,000 un'ts at 12 hourly intervals and doses ranging from 200,000 to 500,000 units at 24 hourly intervals.

(2) With doses of 500,000 units in $0.5 \mathrm{ml}$. of adrenalin solution $1: 1,000$, at 24 hourly intervals, preliminary results in hypopyon ulcer are distinctly promising, both as to a satisfactory end result and rapidity of cure.

(3) Though theoretically less efficient, retrobulbar injection of such doses appears to have clinical possibilities.

\section{REFERENCE}

SorsBy, A. and REED, H. (1948).-Brit. Jl. Ophthal., Vol. XXXI, p. 528.

\section{ON SYMPTOMS OF THE PULSE IN THE CENTRAL RETINAL ARTERY}

BY

\author{
Professor W. KAPUŚCIŃSKI \\ POLAND
}

My "Observations on the pulse and retinal arterial pressure" appeared in the May issue of the British Journal of Ophthalmology. The paper was translated from Polish into English in London and printed without my having read the proofs. Unfortunately the translation contains a great number of errors and in consequence parts of the original text have been misinterpreted. Taking advantage of the courtesy of the Editors of the British Journal of Ophthalmology, I am presenting here again the main points of my considerations on the problem in question. As my first paper was completed two years ago, and as in the meantime I have had the opportunity to make further observations which induced me to modify to a certain extent my former opinion, especially with regard to the measurements of arterial pressure by Bailliart's method, I consider it essential to take these modifications into account in the present paper.

On direct examination of the fundus oculi we notice two kinds of pulse : one of them I would call the physiological, the other the artificial pulse resulting from pressure on the eyeball. The physiological pulse may be perceived in a certain percentage of eyes examined. The first to describe this pulse was O. Becker ${ }^{1}$ in 1872. Limited space does not allow me to submit here a critical review of Becker's observations; suffice it to say that they do not in all instances correspond with the real state of affairs. Ballantyne observed the physiological pulse in all cases which he examined with the aid of Gullstrand's ophthalmoscope. This pulse is based on the following phenomenon: when observing 